\title{
Global Software Engineering for Audio Production
}

\author{
Rodrigo Cordeiro, David N. Prata, and Patrick Letouze, Member, IEDRC
}

\begin{abstract}
This paper deals with the audio production in the context of global software engineering for a distributed geographically environment. This scenario provides new opportunities in the audio industry. The aim of this study is to characterize the different parts of the audio production in an electronic game, showing the possibilities for a more cost-effective in the final product. This goal could be achieved by the use of tools available in the global software engineering industry while maintaining its quality. We used, as basis for this work, a production of 12 instrumental tracks in the model of E-REC (Electronic Recording), by the use of technological resources currently available to record the production via Web. With the proposed model it was possible to reduce costs while maintaining the quality of the entire process during the production. Furthermore, the production of audio across distant geographic regions is useful when you cannot contemplate all the necessary staff in one location. However, some challenges and risks should be taken in attention during the process of audio production regardful the geographically distant, eg. the control of the production process; the delay in the transmission of files via the web, the time set for completion of project. And hence, a possible step where the assembled of the team should be concerned.
\end{abstract}

Index Terms-Audio production, E-REC, films, global software engineering.

\section{INTRODUCTION}

The development of audio game in recent years resembles audio production for movies. This is actually a globalized market involving professionals from different parts of the world: producers, arrangers, authors, dubbing artists and sound engineers, and even bands and singers. This is an unceasing evolution that could expand the development of audio beyond programmers. This paper talks about the audio production, the tools available in the software engineering and the global steps in this process.

Just like in our real life, the sounds surround us denotes an entire environment. The sound generates several reactions for the individuals, like surprise, admiration, and others as frustration and fear [1]. To deals with these reactions, it is necessary not only technical knowledge, but even an appropriate artistic sensitivity to produce correctly and consistently sounds for the game. This can be done by the use of developed graphic art which could embrace percussiveness, melodious, harmonicalness, sound effects and/or dialogues. Likewise, the audio environment presents a series of complex relationships that seeks to provide to the player further real experience to the proposed scenario.

Manuscript received August 10, 2013; revised October 21, 2013

The authors are with the Federal University of Tocantins, CO 77. 001-009 BRA (e-mail: ddnprata@uft.edu.br, casadocordeiro@hotmail.com, Patrick.letouze@gmail.com).
On the other hand, the production team need not necessarily be in the same place. With the internet and modern production software available in the market, it is fully possible and even feasible to produce audio in separate geographically distance for reducing the expenditure with airfare, lodging and provision.

Accordingly, this study was divided as follows: in the second section we describe the steps to achieve a consistent development environment for audio. In section 3, we discussed some requirements in terms of global software engineering to develop the audio. And we comment the many ways to involve professionals from different geographical areas as being a positive factor to the musical production. In Section 4, we quote the most widely used software for music production, which can be introduced within the context of Software Engineering for Global Development to improve audio. For section 5, we present some practical examples by the recording of 12 instrumental tracks. Finally, in section 6, we discuss the challenges and risks that must be taken into account to the production of audio which came up in broken geographical regions.

\section{Stages ANd Processes in the Production OF Audio}

\section{A. Audio Capture}

The process of capturing the audio (recording), is the most important in the production process both in studio and in external field. In fact, today we have access through CDs and the Internet to endless effects libraries. Nevertheless, it is not enough only to pull sound effects from a $\mathrm{CD}$, we also need a good recording and microphone, eg. in the field, to lead to a creativity beyond a library of sound. An audio environment can be destroyed because the presence of bad timbre and neglected by the identification of copied sounds.

In internal recording, like studio, it is necessary the use of quality tools, good mics and class A pre amplifiers, designed to capture the absolute signal integrity. This procedure will ensure to catch the appropriate records throughout Sonora amplitude [2].

Producers need to plan exactly where their objective in terms of quality timbre. It is required both in use appropriate instruments to musical style to be executed as dubbing chosen. For example, it is better effective to capture a voice resembling from a particular personage where the interpretation fits the same style, than performing a possible change in the mix, where you could only get a masking, and never a faithful reproduction.

The team's work should be enhanced by audio partnership with the design staff. This organization is essential to smooth playback environments, in order to achieve a fine reproduction thereof. For example, when moving within an environment as a dense forest or walking in a morass or, up a 
hill, each change must be crafted so that they are perceptible and natural. The audio scene can turn a monotonous scene to an inspiring sensation. The effective use of an audio vocabulary increases the impact of the environment or the personage on the player.

\section{B. Edition}

All recorded stuff must be recorded, it includes the audio captured in the field, the ones to play the effects, or musical stuff like melodic, rhythmic and harmonic. Field recordings usually come with undesirable. These disturbance in audio could be removed by noise reduction software (there are several plug-ins to reduce noise), and recording in studios, may contain minor runtime errors, rhythmic changes, cuts which are required the use of fading out or fade-in and even changes in dynamics that need to be better adjusted.

\section{Mixing}

The mixing process brings all reality of screen events to surface. This effect actually contributes directly to the player engagement. A good mix has to surround the audio as it must also pass the sensation of the audio depth. This process encompasses equalization, compression, reverberance and volume [3]. The mixing technician should have the sensitivity to play audio in the game events, for example, the sound of a car approaching, a personage who goes running from left to the right. This entire process must happen in audio to turn the experience as real as possible. Environments should contain suitable reverberation. It includes both the first plan elements as the background elements must contain a consistent sound reflection.

The music and/or soundtrack usually have their mix done apart. These resources are then added to the final mix with the same effects and adaptations from the reproduced images. From this point, it is necessary the monitoring of producers and sound engineers along with staff of design to achieve a consistent joint of all stuff, so it is easier to get certain tracks sounding uniforms with the settings played in surface.

\section{Mastering}

Mastering can be corrective in nature and also artistic. In this process there are small adjustments to correct equalizations, causing the various tracks to sound homogeneously. Normally the process of recording the soundtrack can use several studios in different environments. It can produce an inconsistent sounding of the music as it relates to different timbres. This process can also place final compression where a volume is defined for all trails. The result causes all sound exactly the same volume without volume fluctuations among one track to another.

\section{REQUIREMENTS FOR DEVELOPMENT OF AUDIO IN GLOBAL SOFTWARE ENGINEERING}

Research in Software Engineering is in growth and its technological resources increasingly available [4]. Furthermore, the easy access to internet has quite feasible the development of audio in different geographical locations. The term e-rec (Electronic Recording) became widely used and means that musicians residing in different cities, states or countries can share recording on a single project via web [5].

Communication is a key factor for the success of distributed software projects, and the engagement of the audio team with the programmers is also required. One point is to define the limits of memory and their wisely use so you can fill the entire vocabulary maximizing as possible the audio memory capability. Another key point is also to define the resolution of the project before starting the whole process, establishing a base resolution. Everyone should record their sounds resolution with equal or higher resolution as the basis. The sampling rate and number of bits must be compatible with the project goal.

For the soundtrack must also be set the followed harmony and progress of the rhythmic BPM (beats per minute). For example, the team will define that the entire audio must be captured on a file type wave of 24 bits per $48 \mathrm{khz}$. In this case, an arranger can create a track in this format in his studio, then he converge it to mp3 and send to an orchestra in another country. The maestro responsible for the orchestra records the sound in the same format to maintain the executed instruments in a real setup. Then the master sends it to the producer responsible for the track, which is located elsewhere. That process makes the cost more attractive. When an executive producer of a developing game project needs a track with gothic style, for example, to a game of terror, he do not need to leave his own site. The producer can contact a music producer elsewhere to find a gothic band for reproducing this specific track.

\section{SOFTWARE TOOLS FOR Musical Production AS GLOBAL SOFTWARE ENGINEERING}

The Global Software Engineering demands software tools to support the special features of distributed environments requirements, which arises due to distance factors [6]. Today there are many software of music production available on the market. The most used are Pro Tools (Avid), Cubase (Steinberg), Sonar (Roland). Pro Tools was the first software to record multi-track audio, and is currently the most widely used software in the professional market of music production. The latest version Advanced Pro Tools 11 HD (Fig. 1) delivers up to 256 audio tracks simultaneous, maximum resolution of 32 bits per $192 \mathrm{Khz}$ and up to 7.1 surround mixing [7]. However, Pro Tools does not offer resources to assist in a distance musical production.

Roland offers the Sonar 8.5 Producer (Fig. 2) which allows working with any interface or control surface. Moreover, Rolland offers an amount of unlimited recording tracks and simultaneous inputs and also the ability to record for many hours without stopping. The software has the ability to operate in 64-bit floating point per $384 \mathrm{kHz}$ [8], this also does not provide resources to collaborate for a production global.

In its 7 th version, Cubase (Fig. 3) is a native system of musical production that met a huge variety of tools and musical resources. Cubase has a console mixing with channel search and plugins. It has a powerful environment for mixing in the box with specter analyzer in the central of the channel. 


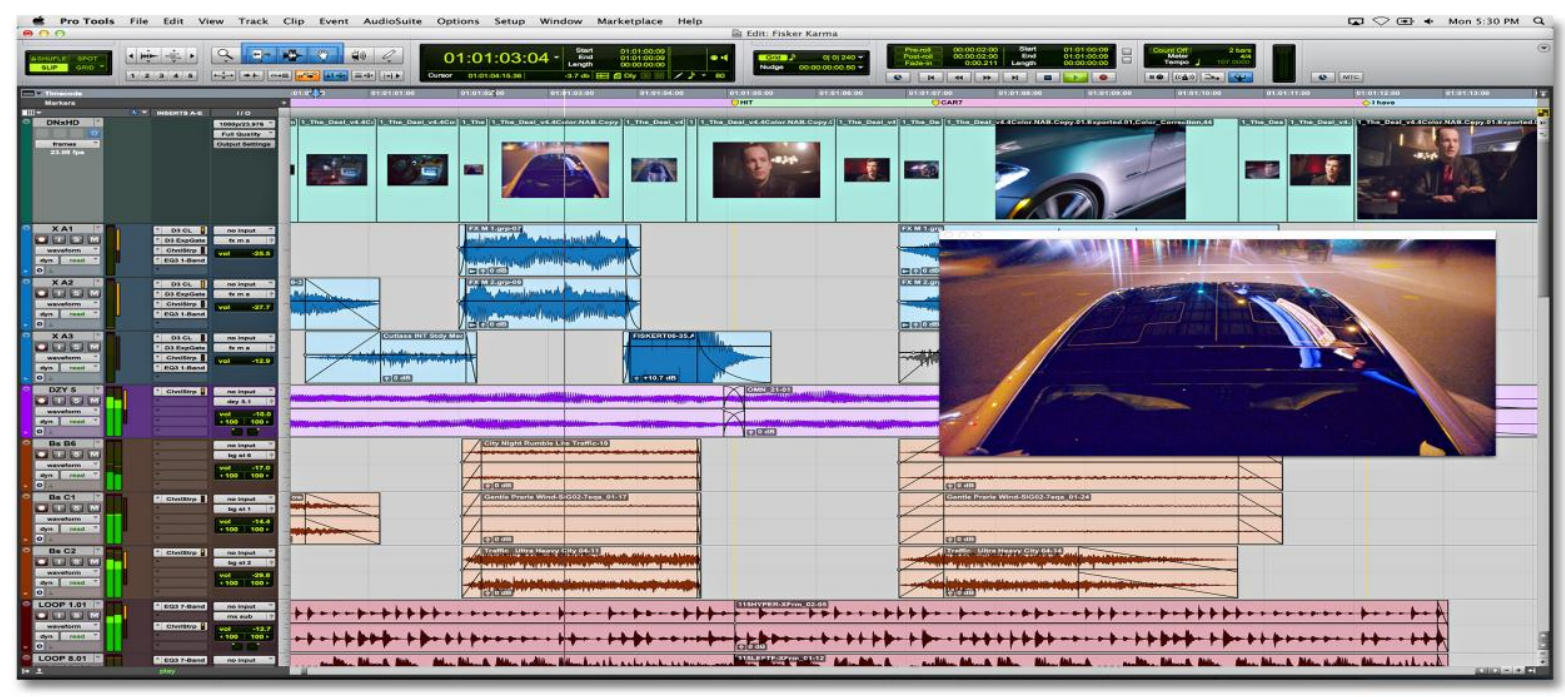

Fig. 1. Tracks in "pro tool".

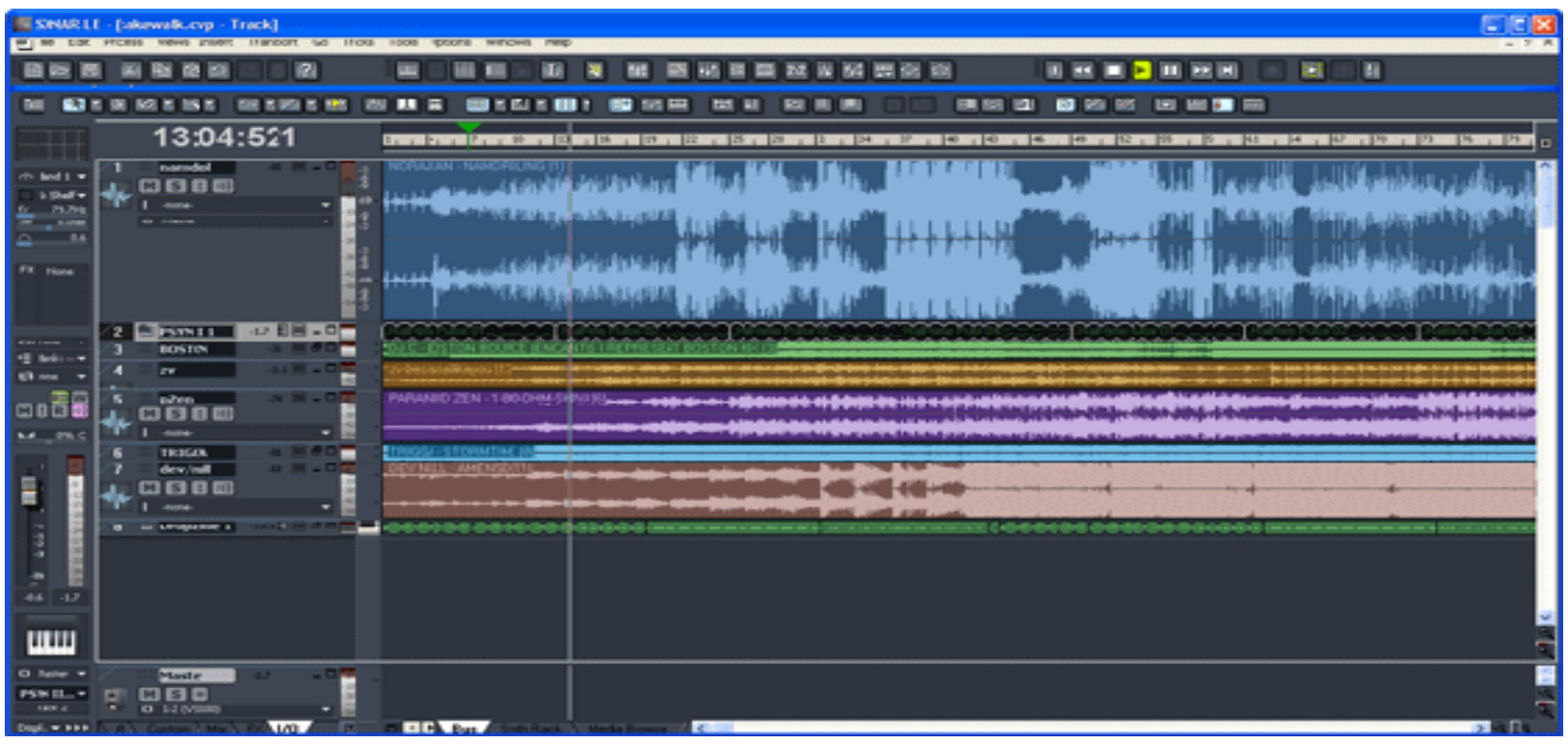

Fig. 2. Tracks in "sonar"

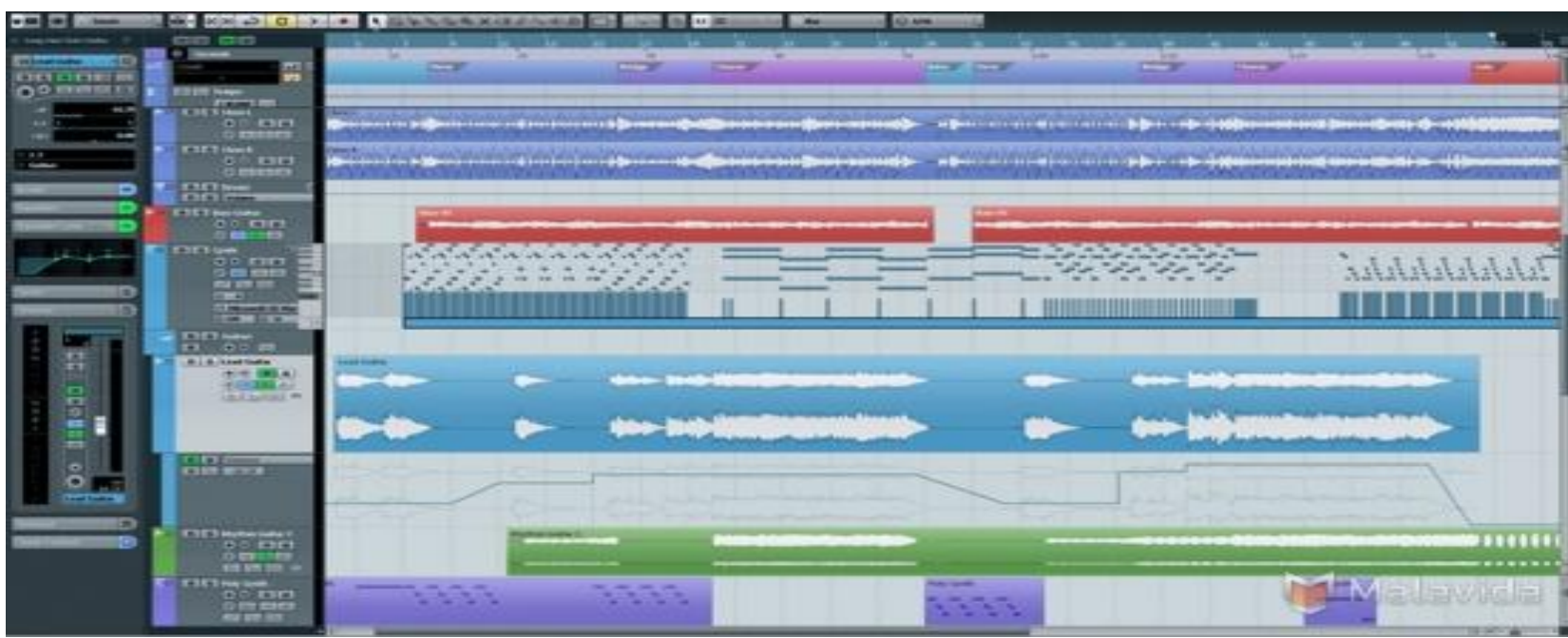

Fig. 3. Tracks in "cubase"

The channel strip has 5 Processors of high quality and also has a track where you can map the harmonic structure of the project. It also works up to 32 bits per $192 \mathrm{kHz}$ [9]. These features can lead to a great advantage when dealing with distributed projects. This tool is the single one in market that offers features for global collaboration. The VST (Virtual Studio Technology) Connect SE Steinberg allows musicians to connect directly to users in Cubase 7 , giving you the 
freedom to collaborate and participate together, even if they are not the same studio, city or country. Other functions are chat and talkback, video and audio in real time bring unlimited opportunities.

\section{PRACTICAL EXAMPLE}

In this section we present case study obtained from the observation of the production of 12 audio tracks during the development of an instrumental project (In Groove of Spirit www.cdbaby.com/cd/rodrigocordeiro). The model used to record was the E-rec [10]. Every project was set to 24-bit resolution and $48 \mathrm{khz}$, keeping files in wave format. The audio software used as default was Cubase (Steinberg). The model E-rec could aggregate quality at a great benefit cost, because there was no need to gather everyone in a same location for producing the tracks. The resolution chosen was determined to maintain the best quality possible during the process, but still keeping the project with a viable size for imports and exports via Web. The audio quality of a CD is 16 bits per $44.1 \mathrm{khz}$ resolution was compatible with the base proposal of the project.

The software Cubase (Steinberg) allowed the production in multiple audio tracks, and even viewing a video track. At the same time, it was possible to use a large variety of plug-ins to process in real time or later during the process of editing and mixing with several virtual instruments.

The production of the CD "No Groove do Espírito" (In the groove of the spirit) had been done in the Home Studio "Casa do Cordeiro" in the city Paraíso of the state of Tocantins Brazil, by Rodrigo Cordeiro; except for the guitars and basses that had been recorded in the city Goiânia of the state of Goiás - Brazil, by Mardem Júnior. Also, edition, mixing and mastering had been done by Rodrigo Cordeiro.

The musicians of the CD are: drums - Rodrigo Cordeiro; basses - Eurípedes Batista, Vamilton Paulo and Mardem Júnior; guitars - Rodrigo Cordeiro, Frederico and Vicente Neto; keyboard - Gilmar Robson. The softwares that had been used are Cubas $3 \mathrm{SX}$ with the plugins Nomad Factory, Sony, Waves, Steinberg ME, VST Dynamics, Timeworks and TC Works. The virtual instruments were Reason Adapted for M-Audio, Korg, Embrace, Rhino, Mercury, Modular System and B4; and the simulators of instruments amplifiers were Amplitude and Guitar Rig. The pre-amplifiers that had been used for recording were Focusrite Platinum Octopre LE. Arcano Artube 200 and Xênix. The microphones were Mic C01 Sansom and Mic for drums Arcano. For the production using the web, E-rec had been used for the musical production. It was created by Sallaberry and it can be found in.

First the pre-production was done at "Casa do Cordeiro". Then the drums were recorded and exported in mp3. The mp3 file was sent through Hotmail to the Studio in Goiânia, where it was imported to Cubase (mp3 $320 \mathrm{kbits}$ at $44.1 \mathrm{kHz}$, Stereo in Wave 24 bits at $48 \mathrm{kHz}$ ). After that, bass and guitar were recorded and exported separately to be sent back in Wave 24 bits format at $48 \mathrm{kHz}$ using Hotmail. However, sometimes it had been used the service provided by www.sendspace.com to send more tracks simultaneously, because some musics had 4 guitars and one bass. That strategy intended to avoid multiple e-mails. Communication had been done through Facebook's chat. Video resources were not been used.

\section{DISCUSSION}

After all presented, we can conclude that globally dispersed software development, as a musical production, should consider some challenges and risks (despite the benefits obtained.) A poor communication has been identified as a major obstacle to a successful collaboration [11]. Distributed projects are especially threatened by information gaps. To keep control and coordination of the project becomes more difficult since there isn't the same face to face interaction of a development conducted in the same environment. It can occur in different interpretations with the proposed initially goal, leading to a longer time period to recording the project. Some styles of music tracks has a better results when the musicians playing live, as recording together in the same room. It must be taken into consideration especially when there is engagement of a band or symphony orchestra on track. Another factor is the waste of time with files transmission via the web. It can be laborious due to delay transfers of large file formats, and also the possible conversions formats to wave, $\mathrm{mp} 3$ and vice versa, depending on the Internet speedy.

The final mix is a step which music producer, engineers and designers should be in the same studio. For every process to have cohesive execution, as audio environment versus design environment, the process should be done in a dedicated room. For the mixing of visual audio where there are further than audio monitors of reference, but also one of video, there must be a perfect cohesion among audio, scenery and events.

Compared features offered by Cubase 7 and the others cited in this work, this tool is currently the software that provides a better collaboration available to Global Software Engineering, allowing professionals dispersed in geographically distant regions to work through Connect VST SE Steinberg. In order, the audio production accomplished in geographically distant can be more time consuming. For a choose to develop soundtracks and audio environments in geographically distant, we must consider potential expenditures, the set time for delivery of the finished project and also which styles were set to compose tracks.

\section{ACKNOWLEDGMENT}

We thank the musicians, composers and arrangers who participated in the project "Groove in the Spirit": Mardem Júnior, Vamilon Paulo, Vicente Neto, Marcelo, Frederico, Gilmar Robson, Júnior Pimenta.

\section{REFERENCES}

[1] D. Berstein. (November 1997). Creating an Interactive Audio Environment. The Art and Business of Making Games Gamasutra. [Online]. Available: http://www.gamasutra.com/view/feature/3238/creating_an_interactive _audio_.php

[2] D. M. Huber and R. E. Runstein, Técnicas Modernas de Gravação de Áudio, 7 Edição, editora Elsevier-Campos, 2011, ch. 7, pp. 73-107. 
[3] L. R. Shum, "A construção de paisagens sonoras em games a partir dos modelos estruturais de Samsel e wimberley," in Proc. Art and Design Track, Belo Horizonte, Nov 2008, pp. 16-23.

[4] J. P. Rodriguez, A. Vizcaíno, M. Piattini, and S. Beecham, "Tools used in global software engineering: A systematic mapping review,' Journal of Information and Software Technology, vol. 54, issue. 7, pp. 663-685, July, 2012.

[5] K. Stapel and K. Schneider, "Managing Knowledge on communication and information flow in global software projects," Expert Systems, John Wiley \& Sons Ltd, Sep 2012, in press.

[6] L. C. Meneguette, "Áudio dinâmico para games: conceitos fundamentais e procedimentos de composição adaptativa," in Proc. SB Games, Art and Design Track, Salvador-BA, Nov. 2011, pp. 1-10.

[7] K. Snider. (2007). A heretical approach to the screen musical. Recording Angels. [Online]. Available: http://www.woollymammoth.com/credo/assets/credo_recording_articl es.pdf

[8] R. Paul. (2007). Review: Roland CakeWalk. Sonar. Cakewalk Netcom. [Online]. Available: http://www.rickpaul.info/articles/cakewalk-sonar-7-producer-review.p df

[9] A. Price. (2013). Cubase Tutorial: Mastering in Cubase. MusicTech Magazine. [Online]. Available: http://www.musictech.net/2013/08/cubase-tutorial-mastering/
[10] Sallaberry, Manual Prático de Produção Musical, Editora Música e Tecnologia, 2008, pp. 50-55.

[11] D. N. Nakano, R. Nakamura, and L. O. Sakuda, "Produção e operação em games: visão geral e Perspectivas," in Proc. SB Games, Industry Track, Brasília-DF, Nov. 2012, pp. 6-12.

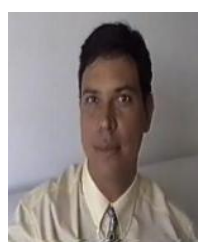

David Prata was born in Goiânia, Brazil on 18th September, 1965. Dr. Prata completed his Bachelor of Computer Science in 1992. Then on, he went to complete his specializing in Academician. He worked as system analyst to Tocantins Government, being in charge for the accountability and financial systems. Later, he successfully completed his Master Degree in Computer Science from Campina Grande Federal University, with application research in education in 2000 year. He coordinated graduate and undergraduate courses in computer science at Alagoas Faculty in Maceio, Brazil. He was allotted to Federal University of Alagoas in 2006. Then, he moved to Federal University of Tocantins. His doctoral was developed in part at Carnegie Mellon University, USA, completed in 2008. He is currently coordinating a Master Degree in Computational Model. His research interests are education and ecosystems. Dr. Patrick Letouze is with the Computer Science Department at the Federal University of Tocantins, and currently he is the director of the Software Development Nucleus - NDS. 